\title{
Public health: a multi-faceted issue
}

\author{
Henning Cramer
}

Published online: 28 February 2013

(C) Springer-Verlag Berlin Heidelberg 2013

Prize question: What do strategies to provide fluoride-free water in Ethiopia, the weather in Hong Kong, and scientific publications on patient safety indicators have in common? "Not much", you might say, and from a general point of view, you would probably be right. In the context of Public Health, however, there is a common ground.

Generally accepted definitions of Public Health claim that it aims at preventing disease, prolonging life and promoting the health of (sub-groups of) the members of society (Winslow 1920; World Health Organization 1952; Committee of Inquiry into the Future Development of the Public Health Function 1988). These aims implicate several specific characteristics, e.g.:

1. That Public Health is a worldwide issue (Centers for Disease Control and Prevention 2011)

2. That Public Health researchers use a broad range of methods (Quine and Taylor 1998)

3. That Public Health, in fact, is not a genuine discipline in and of itself, but rather that different disciplines engage in Public Health (see Hurrelmann et al. 2012, but also see Winslow 1920!)

Public Health thus follows an international, multidisciplinary und multi-method approach. Most issues of the Journal of Public Health reflect this, and so does the one at hand with its reports on studies from Africa, Asia and Europe (one of which was furthermore conducted by American researchers). Authors come from fields as different as aquatic science, epidemiology, medicine, meteorology, (micro)biology, nursing, psychology etc. Methods reaching from natural scientific analyses to psychological tests and "classical" methods of the social sciences (different forms of

H. Cramer $(\bowtie)$

Lünener Straße 61,

59379 Selm, Germany

e-mail: henning.cramer@gmx.de quantitative and qualitative surveys and interviews of individuals and of groups) all the way up to the analysis of scientific literature have been applied.

Despite these differences, in some way or other, all the articles in this issue of the Journal of Public Health add to the knowledge needed to prevent disease, prolong life and promote health:

- Mahesh et al. evaluated smear test vs. culture test diagnosis of pulmonary tuberculosis (TB), using sputum samples from the patients of an Indian hospitalbased TB centre.

- Omokhodion and Adebayo assessed occupational hazards and health-related problems of Nigerian butchers, applying a questionnaire-based survey and physical examination.

- Li et al. examined season- and temperature-related effects on the relationship between air pollution and mortality in a Chinese metropolis.

- Cramer et al. surveyed German nurses on their perception concerning causes of the occurrence of health care errors.

- Asgary et al. used focus groups to explore the perception of stigma and discrimination towards HIV and AIDS patients in Ethiopia.

- Zoidaki et al. studied the magnitude of musculoskeletal disorders among Greek dentists by means of a selfadministered questionnaire.

- Fong and Ma evaluated the relationship of meteorological factors and admissions to a Hong Kong hospital for respiratory and cardiovascular reasons.

- Huber and Mosler used structured face-to-face interviews to examine factors that explain preferences concerning two fluoride-free water options in Ethiopia.

- Kamal et al. applied a well-recognized health survey to assess the quality of life among Egypt hemodialysis patients. 
- Kuske et al. describe and prioritize indicators of patient safety based on a systematic review.

- Fearnley et al. comment on the necessity of including gambling-related harm treatment into mainstream service delivery.

In summary, the findings and implications of the articles included in this issue of the Journal of Public Health demonstrate the benefits of the multi-faceted nature of Public Health, which brings us back to the prize question: What do fluoride-free water provision strategies in Ethiopia, the Hong Kong weather, and literature on patient safety indicators have in common? Well, that is easy. From the perspective of Public Health, all three are useful starting points when it comes to contributing to its original aims of preventing disease, prolonging life, and promoting health.

\section{References}

Centers for Disease Control and Prevention (2011) Ten great public health achievements: worldwide, 2001-2010. Morb Mort Wkly Rep 60:814-818

Committee of Inquiry into the Future Development of the Public Health Function (1988) Public health in England. Report of the Committee of Inquiry into the future development of the public health function. HMSO, London

Hurrelmann K, Laaser U, Razum O (2012) Entwicklung und Perspektiven der Gesundheitswissenschaften in Deutschland. In: Hurrelmann K, Razum O (eds) Handbuch Gesundheitswissenschaft. 5., vollständig überarbeitete Auflage. Beltz Juventa, Weinheim, pp 15-51

Quine S, Taylor R (1998) Methodological strategies. In: Kerr C, Taylor R, Heard G (eds) Handbook of public health methods. McGraw Hill, Sydney, pp 17-23

Winslow CEA (1920) The untilled fields of public health. Science 51:23-33

World Health Organization (1952) Expert Committee on Public Health Administration. Technical report series no. 55. World Health Organization, Geneva 